\title{
Energy Budgets in the Neptune Whelk Neptunea arthritica Population in Usu Cove, Funka Bay, Hokkaido
}

\author{
Katsuaki Fujinaga $^{1)}$, Anthony S. Ilano ${ }^{2)}$ and Shigeru Nakao ${ }^{2)}$ \\ ${ }^{1)}$ Department of Liberal Arts, Dohto University, Monbetsu Campus, 7-1 Ochiishi-cho, Monbetsu, \\ Hokkaido 094-8582, Japan \\ ${ }^{2)}$ Faculty of Fisheries, Hokkaido University, 3-1-1 Minato-cho, Hakodate, Hokkaido 041-8611, Japan
}

\begin{abstract}
Energy budgets in Neptunea arthritica, a species with significantly different proportions of assimilated energy directed to reproduction in males and females, were estimated based on sex ratio (male : female), assimilated energy and energy allocation in each age class, and seasonal changes in density. The sex ratio changed with every sample, but the energy budgets in year-classes were framed using the interpolated mean ratio of 0.95 during the period of density measurements. The several observed energy budget patterns in the neptune whelk very nearly corresponded to the growth stages of hatchling, immature, and adult. The biomass in the hatchling fraction of the population did not increase very much regardless of relatively high assimilation at that stage, because of the rather heavy mortality as compared with recruitment. In contrast, in the immature fraction, final biomass increased considerably as compared with the initial state, as the result of high assimilation and growth with little mortality. Finally, in the adult fraction, biomass substantially decreased from the initial to final state due to assimilation only roughly equalling initial biomass, or falling short of doing so, thus resulting in little or no growth, and to mortality being roughly equal to or exceeding assimilation. The turnover ratio of the neptune whelk population in the investigation period showed a very low value of 0.42 , reflecting a drastic mortality in the older adult population. The energy budget patterns in the three growth stages and the migration pattern in immatures suggest that construction of a nursery ground for immature individuals should be a very important consideration in efforts to propagate the neptune whelk.
\end{abstract}

Key words: energy budget, growth stage, Neptunea arthritica, nursery ground, sex ratio, turnover ratio

\section{INTRODUCTION}

In the 1970s the population of the neptune whelk Neptunea arthritica in several embayments in Hokkaido, purportedly decreased due to overfishing (e.g. Itoh \& Tachizawa 1981); additionally, in the 1980s the whelk fishery in many embayments was subjected to de-

Received August 10, 2000: Accepted April 23, 2001 structive damage by TBT (tributyltin) compounds (e.g. Fujinaga \& Nakao 1999a). The use of TBT-based antifouling paints on boats of less than $25 \mathrm{~m}$ in length and on fish-pen nets was prohibited in 1990. Following this, the relative penis size index of neptune whelks in the present study site, Usu Cove, has drastically declined, which suggests that female neptune whelks in this cove have been recovering from imposex (Fujinaga \& Nakao 1999a). Even now, though, the whelk fishery is still in abeyance in many embayments, including Usu Cove. In the future, to restore the whelk fishery, it will 
be necessary to monitor the recovery from imposex and carry out artificial propagation based on the ecological properties of the species. A study of the species' biological production would provide a quantitative base for designing the means of propagation.

Information on biological production is important because it provides an interpretation of distribution and migration from the viewpoint of energy intake and a weight-based estimate of the optimum catch in terms of energy budget and turnover ratio. So far, for the neptune whelk, the seasonal change in energy assimila-

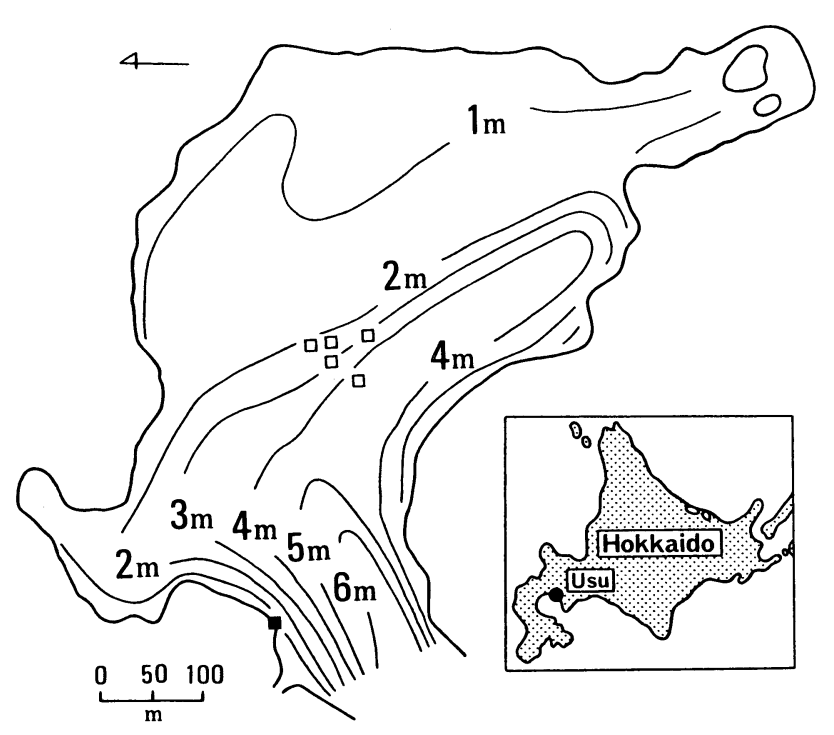

Fig. 1. Map of Usu Cove showing locations of oyster culture rafts (open quadrangles), the station (solid quadrangle) where water temperature was measured, and approximate depth contours. tion in immature and mature whelks and the assimilation in each age class have been reported (Fujinaga \& Nakao 1997). In this species the proportions of assimilated energy directed to reproduction greatly differ between male and female, that in females reaching three to six times that in males, which mainly reflects the production of egg capsules by the females (Fujinaga \& Nakao 1997).

In the present study, seasonal changes in the sex ratio of adult neptune whelks were examined, and then the energy budget of each year class was estimated based on assimilation and allocation of energy in each age class (Fujinaga \& Nakao 1997) and the seasonal changes in density of each year class (Fujinaga \& Nakao 1996).

\section{MATERIALS AND METHODS}

The study was carried out in Usu Cove $\left(42^{\circ} 30^{\prime} \mathrm{N}\right.$, $140^{\circ} 47^{\prime} \mathrm{E}$ ), located in the northern part of Funka Bay, Hokkaido (Fig. 1). A hanging culture of oyster rafts (Crassostrea gigas) was operated in the central part of the bay.

The sex ratios (male : female) of $N$. arthritica were investigated from April to September, 1978, and from May, 1985, to March, 1986. Neptune whelks were collected by SCUBA diving, mainly in the vicinity of the oyster rafts. Their sex was judged in 1978 based on the presence of a penis, because at that time mature females had no penis. In 1985-86 sex was discriminated based on the presence of the capsule gland and albumin gland and the colour of the gonad, because of the imposition of a penis nearly as large as a male's penis on ma-

Table 1. The density $\left(\right.$ No. $/ \mathrm{m}^{2}$ ) of Neptunea arthritica of each year-class in each month between May, 1980, and May, 1981 in Usu Cove.

\begin{tabular}{|c|c|c|c|c|c|c|c|}
\hline \multirow{2}{*}{\multicolumn{2}{|c|}{ Month }} & \multicolumn{6}{|c|}{ Year-class (Age) } \\
\hline & & \multirow[t]{2}{*}{$1980(0)$} & \multirow{2}{*}{$\frac{1979(0-\mathrm{I})}{0.427}$} & \multirow{2}{*}{$\frac{1978(\mathrm{I}-\mathrm{II})}{1.150}$} & \multirow{2}{*}{$\frac{1977(\text { II }- \text { III })}{1.486}$} & \multirow{2}{*}{$\frac{1976(\text { III }- \text { IV })}{1.781}$} & \multirow{2}{*}{$\frac{\leqq 1975(\geqq \mathrm{IV}-\geqq \mathrm{V})}{1.130}$} \\
\hline 1980 & May & & & & & & \\
\hline & June & & 0.277 & 0.770 & 1.169 & 1.520 & 0.710 \\
\hline & July & & 0.395 & 0.876 & 1.116 & 1.132 & 0.416 \\
\hline & Aug. & & 0.508 & 1.011 & 1.009 & 0.653 & 0.185 \\
\hline & Sep. & 0 & 0.605 & 1.023 & 0.923 & 0.545 & 0.183 \\
\hline & Oct. & 0.200 & 0.584 & 0.952 & 1.010 & 0.558 & 0.165 \\
\hline & Nov. & 0.247 & 0.523 & 1.118 & 1.270 & 0.658 & 0.154 \\
\hline & Dec. & 0.217 & 0.468 & 1.120 & 1.480 & 0.683 & 0.148 \\
\hline \multirow[t]{5}{*}{1981} & Jan. & 0.179 & 0.413 & 0.944 & 1.457 & 0.581 & 0.117 \\
\hline & Feb. & 0.107 & 0.383 & 0.925 & 1.336 & 0.502 & 0.102 \\
\hline & Mar. & 0.054 & 0.369 & 0.934 & 1.264 & 0.446 & 0.091 \\
\hline & Apr. & 0.090 & 0.453 & 1.146 & 1.479 & 0.500 & 0.100 \\
\hline & May & 0.124 & 0.534 & 1.350 & 1.687 & 0.552 & 0.109 \\
\hline
\end{tabular}


ture females (Fujinaga \& Nakao 1999a). Neptune whelks in Usu Cove reach their first sexual maturity at $50 \mathrm{~mm}$ shell height in males and $60 \mathrm{~mm}$ shell height in females (Fujinaga 1985). In the present study, the sex ratios of whelks larger than $60 \mathrm{~mm}$ in shell height, when all should have attained sexual maturity, were ex- amined.

The energy budget in each year class was constructed using the results of population structure and mortality (Fujinaga \& Nakao 1996), and seasonal changes in energy assimilation (Fujinaga \& Nakao 1997).

Table 2. Dry weight ( $\mathrm{g}$ ) of body parts in each month in each age-class, calculated from the regression equations for shell height-soft body weight (excluding gonad weight), shell height-gonad weight, and shell height-shell weight. BP: body part, So: soft body (excluding the gonad in the adult), Go: gonad, Sh: shell.

Immature

\begin{tabular}{|c|c|c|c|c|c|c|c|c|c|c|c|c|c|}
\hline \multirow{2}{*}{ Age } & \multirow{2}{*}{$\mathrm{BP}$} & \multicolumn{12}{|c|}{ Month } \\
\hline & & July & Aug. & Sep. & Oct. & Nov. & Dec. & Jan. & Feb. & Mar. & Apr. & May & June \\
\hline \multirow{2}{*}{0} & So & & & 0.002 & 0.003 & 0.006 & 0.008 & 0.010 & 0.012 & 0.017 & 0.020 & 0.017 & 0.020 \\
\hline & $\mathrm{Sh}$ & & & 0.211 & 0.256 & 0.306 & 0.358 & 0.413 & 0.471 & 0.530 & 0.590 & 0.649 & 0.709 \\
\hline \multirow{2}{*}{ I } & So & 0.028 & 0.049 & 0.071 & 0.097 & 0.138 & 0.161 & 0.193 & 0.211 & 0.238 & 0.250 & 0.234 & 0.241 \\
\hline & $\mathrm{Sh}$ & 0.954 & 1.301 & 1.640 & 1.953 & 2.225 & 2.452 & 2.640 & 2.788 & 2.905 & 2.997 & 3.065 & 3.120 \\
\hline \multirow{2}{*}{ II } & So & 0.303 & 0.446 & 0.599 & 0.750 & 0.799 & 0.896 & 1.050 & 1.121 & 1.202 & 1.247 & 1.322 & 1.352 \\
\hline & $\mathrm{Sh}$ & 3.678 & 4.582 & 5.411 & 6.133 & 6.741 & 7.244 & 7.646 & 7.966 & 8.215 & 8.411 & 8.562 & 8.674 \\
\hline \multirow{2}{*}{ III } & So & 1.816 & 2.169 & 2.557 & & & & & & & & & \\
\hline & $\mathrm{Sh}$ & 10.179 & 11.262 & 12.163 & & & & & & & & & \\
\hline
\end{tabular}

Male

\begin{tabular}{|c|c|c|c|c|c|c|c|c|c|c|c|c|c|}
\hline \multirow{2}{*}{ Age } & \multirow{2}{*}{$\mathrm{BP}$} & \multicolumn{12}{|c|}{ Month } \\
\hline & & July & Aug. & Sep. & Oct. & Nov. & Dec. & Jan. & Feb. & Mar. & Apr. & May & June \\
\hline \multirow{3}{*}{ II } & So & & & & & & & & & & 1.128 & 1.213 & 1.295 \\
\hline & Go & & & & & & & & & & 0.006 & 0.007 & 0.007 \\
\hline & $\mathrm{Sh}$ & & & & & & & & & & 8.496 & 8.645 & 8.757 \\
\hline \multirow{3}{*}{ III } & So & 1.496 & 1.865 & 2.157 & 2.388 & 2.592 & 2.752 & 2.736 & 2.834 & 3.003 & 3.061 & 3.141 & 3.189 \\
\hline & Go & 0.006 & 0.008 & 0.030 & 0.079 & 0.072 & 0.040 & 0.030 & 0.029 & 0.022 & 0.022 & 0.023 & 0.023 \\
\hline & Sh & 10.241 & 11.307 & 12.192 & 12.908 & 13.478 & 13.928 & 14.279 & 14.554 & 14.761 & 14.922 & 15.051 & 15.142 \\
\hline \multirow{3}{*}{ IV } & So & 3.601 & 4.167 & 4.827 & 5.201 & 5.604 & 5.859 & 5.813 & 5.969 & 6.120 & 6.209 & 6.202 & 6.115 \\
\hline & Go & 0.023 & 0.028 & 0.086 & 0.205 & 0.164 & 0.102 & 0.069 & 0.060 & 0.053 & 0.054 & 0.055 & 0.056 \\
\hline & $\mathrm{Sh}$ & 16.867 & 18.122 & 19.136 & 19.952 & 20.599 & 21.109 & 21.504 & 21.816 & 22.054 & 22.235 & 22.376 & 22.488 \\
\hline \multirow{3}{*}{$\mathrm{V}$} & So & 6.571 & 7.157 & 8.168 & 8.478 & 8.914 & 9.060 & 8.836 & 8.899 & 8.861 & 8.891 & 8.699 & 8.403 \\
\hline & Go & 0.059 & 0.067 & 0.171 & 0.374 & 0.270 & 0.174 & 0.108 & 0.088 & 0.085 & 0.085 & 0.086 & 0.086 \\
\hline & $\mathrm{Sh}$ & 23.737 & 24.891 & 25.686 & 26.226 & 26.591 & 26.830 & 26.998 & 27.102 & 27.174 & 27.226 & 27.252 & 27.278 \\
\hline
\end{tabular}

Female

\begin{tabular}{|c|c|c|c|c|c|c|c|c|c|c|c|c|c|}
\hline \multirow{2}{*}{ Age } & \multirow{2}{*}{ BP } & \multicolumn{12}{|c|}{ Month } \\
\hline & & July & Aug. & Sep. & Oct. & Nov. & Dec. & Jan. & Feb. & Mar. & Apr. & May & June \\
\hline \multirow{3}{*}{ III } & So & & & & 2.632 & 2.957 & 3.112 & 3.090 & 3.190 & 3.392 & 3.445 & 3.584 & 3.572 \\
\hline & Go & & & & 0.069 & 0.052 & 0.060 & 0.111 & 0.118 & 0.118 & 0.123 & 0.119 & 0.186 \\
\hline & $\mathrm{Sh}$ & & & & 12.024 & 12.625 & 13.102 & 13.475 & 13.768 & 13.989 & 14.162 & 14.300 & 14.397 \\
\hline \multirow{3}{*}{ IV } & So & 3.683 & 4.469 & 4.892 & 5.224 & 5.726 & 5.949 & 6.093 & 6.240 & 6.030 & 6.101 & 6.663 & 6.454 \\
\hline & Go & 0.107 & 0.059 & 0.172 & 0.189 & 0.318 & 0.353 & 0.455 & 0.478 & 0.503 & 0.518 & 0.562 & 0.364 \\
\hline & $\mathrm{Sh}$ & 16.260 & 17.632 & 18.749 & 19.653 & 20.374 & 20.943 & 21.386 & 21.737 & 22.005 & 22.209 & 22.367 & 22.494 \\
\hline \multirow{3}{*}{$\mathrm{V}$} & So & 6.340 & 7.171 & 7.777 & 8.036 & 8.524 & 8.643 & 8.884 & 8.941 & 8.133 & 8.155 & 9.069 & 8.615 \\
\hline & Go & 0.163 & 0.150 & 0.340 & 0.357 & 0.946 & 0.983 & 0.997 & 1.011 & 1.068 & 1.075 & 1.213 & 0.504 \\
\hline & Sh & 23.908 & 25.223 & 26.134 & 26.755 & 27.176 & 27.451 & 27.645 & 27.765 & 27.848 & 27.908 & 27.938 & 27.968 \\
\hline
\end{tabular}


Table 3. Monthly average water temperature near the mouth of Usu Cove, measured from August, 1977, to November, 1978.

\begin{tabular}{cc}
\hline Month & Water temperature $\left({ }^{\circ} \mathrm{C}\right)$ \\
\hline Jan. & 4.6 \\
Feb. & 2.5 \\
Mar. & 3.2 \\
Apr. & 5.5 \\
May & 10.7 \\
June & 16.2 \\
July & 22.1 \\
Aug. & 23.0 \\
Sep. & 19.7 \\
Oct. & 15.6 \\
Nov. & 11.3 \\
Dec. & 7.7 \\
\hline
\end{tabular}

The density in each year class was investigated monthly from May, 1980 to April, 1981, except for winter, while SCUBA diving. The determination of the density was done by using two $1 \times 1 \mathrm{~m}^{2}$ - quadrats placed in adjacent positions at 100 stations. The age of individuals was estimated on the basis of previously determined growth formulae for neptune whelk in Usu Cove (Fujinaga 1987). The densities in each year class between May, 1980, and May, 1981, are shown in Table 1, and those in January, March, and May of 1981 were calculated by interpolation or extrapolation using the densities measured in December, 1980, February, 1981, and April, 1981.

In a study on seasonal changes in assimilation (Fujinaga \& Nakao 1997), shell growth was adduced to elucidate the difference in energy allocation between immature and adult whelks. Assimilation (excluding losses due to mucus production and excretion) was estimated based on shell height using the growth formulae (Fujinaga 1987); regression equations for shell heightsoft body weight (excluding gonad weight), shell height-gonad weight, and shell height - shell weight; and the multiple regression equation between oxygen consumption, body weight, and water temperature. The soft body weight, gonad weight, and shell weight for each month in each age class are shown in Table 2. Soft body and shell growth increments and gonad production were obtained by multiplying the difference in weight between two successive months by the respective energy content $\left(\mathrm{KJ} \cdot \mathrm{g}\right.$ dry $\left.\mathrm{wt}^{-1}\right)$. Respiration rates were estimated by substituting the water temperature (Table 3 ) and the results in Table 2 in the following multiple regression equation: $R=0.060 W^{0.090} 10^{0.049}$ (where $R$ : oxygen consumption rate $\left(\mathrm{mg} \mathrm{O}_{2} \bullet\right.$ ind. $\left.^{-1} \cdot \mathrm{h}^{-1}\right), W$ : individual dry weight $(\mathrm{g})$, and $t$ : water temperature $\left({ }^{\circ} \mathrm{C}\right)$ ).

The budget equation for a population during a given period in a given area can be represented as follows, partially modified from an equation presented by Kawanabe (1969):

Initial biomass + Consumption + Immigration + Recruitment $=$ Growth + Reproduction + Respiration + Mucus production + Excreta + Egesta + Predation loss + Natural mortality + Yield + Emigration + Final biomass

where, Consumption - Egesta $=$ Assimilation. In gastropods, excretion loss is likely to be insignificant (Branch 1981; Wright \& Hartnoll 1981; Peck et al. 1987); furthermore, predation loss in the neptune whelk is thought to be very slight after hatching (Fujinaga \& Nakao 1996). Taking these matters into account, the above budget equation, expressed in terms of assimilation, can be amended as follows:

Initial biomass + Assimilation + Immigration + Recruitment $=$ Growth + Reproduction + Respiration + Mucus production + Natural mortality + Yield + Emigration + Final biomass

Peck et al. (1987) quantified mucus production in the ormer Haliotis tuberculata. Because they investigated the energy budget of that species in terms of ingestion, the proportion of mucus production to assimilation was calculated in the present study. As a result, $28 \%$ of the assimilated energy in immature whelks, and 36\% (the average of 3 different-sized whelks with a value in reproduction) in adult whelks, was regarded herein as being spent on mucus production; moreover, the rate of mucus production was premised herein to show no change throughout a year. Also, the three terms of natural mortality, yield, and emigration were combined together herein as "mortality", because it was impossible to specify the causes of decreases in density in the present study.

In calculating the energy budget of a population, if the weight and the number of individuals at times $t_{1}$ and $t_{2}$ are $W_{1}, W_{2}$, and $N_{1}, N_{2}$, respectively, the mean weight and mean number of individuals between the times $t_{1}$ and $t_{2}$ are $\bar{W}\left(=\left(W_{1}+W_{2}\right) / 2\right)$ and $\bar{N}\left(=\left(N_{1}+\right.\right.$ $\left.N_{2}\right) / 2$ ), and the increments in the weight and the number of individuals during the time from $t_{1}$ to $t_{2}$ are $\triangle W$ $\left(=W_{2}-W_{1}\right)$ and $\triangle N\left(=N_{2}-N_{1}\right)$, respectively; in addition, $\triangle W \times \bar{N}$ indicates net production when positive and degrowth or ejection of gonad output when negative, and $\triangle N \times \bar{W}$ reflects net recruitment or immigration when positive and mortality when negative. 


\section{RESULTS}

\section{Sex ratio}

The sex ratio of adult Neptunea arthritica changed with each investigation (Fig. 2). The sex ratios (male : female) ranged from 0.51 to 0.92 during the relatively short period of April to September in 1978. In the period between May, 1985, and March, 1986, the ratios showed a greater fluctuation, from 1.08 in November, 1985, to 2.18 in January, 1986, because of the paucity of specimens. Also, the sex ratios considerably differed between 1978 and 1985-1986, being much higher in the latter period than in the former. Lumping all specimens together from each of these two periods, the values were 0.70 in the former period and 1.47 in the latter.

\section{Energy budget}

In the neptune whelk the energy directed to reproduction significantly differs between males and females (Fujinaga \& Nakao 1997). This indicates that, in estimating the energy budget of a population, a more precise budget can be obtained by the separation of males and females in modelling the system. In the present study, no distinct pattern of seasonal changes in the sex ratio was found. So, using the lumped sex ratios of 0.70 and 1.47 calculated above for populations in 1978 and 1985-1986, respectively, the mean ratio of males to females during the investigation period (the middle point of time being mid-October, 1980) was calculated by interpolation, and the value of 0.95 was obtained. Then, regarding the sex ratio in the adult whelks as 0.95 on average during the investigation period, the energy budget of each year class was calculated based on the seasonal changes in energy assimilation and allocation of each age class, and the seasonal changes in density of each year class (Figs. 3 and 4). Because shell growth was included in growth, in the present study, energy directed to the shell is exhibited in parentheses in the terms necessary for the calculation of the turnover ratio $(P / B)$.

The energy budget patterns of the year classes were divided into four types on the basis of relations among initial biomass (recruitment), assimilation, growth, mortality, and final biomass.

In the 1980 year class, assimilation was 7.0 times as large as recruitment, but final biomass did not exhibit such a high increase, reaching only 2.3 times greater than at recruitment, owing to mortality claiming one-third of the assimilation. In contrast, in the

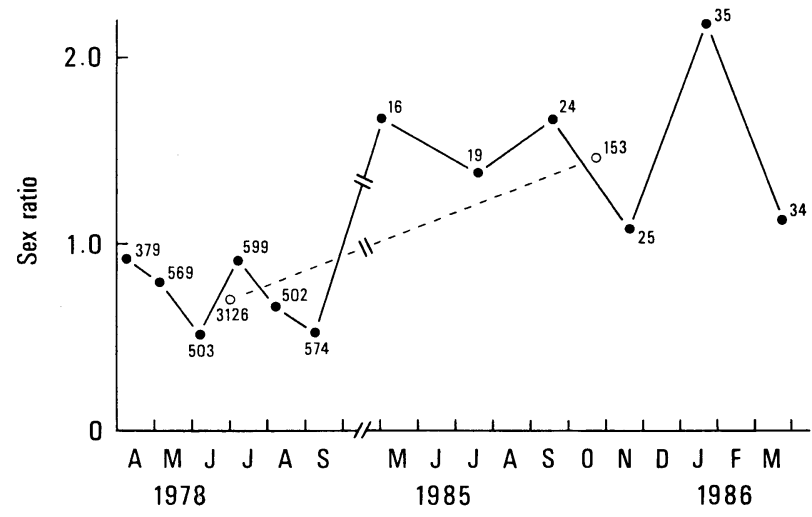

Fig. 2. Seasonal changes in the sex ratio (male : female) of Neptunea arthritica of more than $60 \mathrm{~mm}$ in shell height. Open circles indicate the ratio calculated from the lumped specimens of the two sampling period. The numeral by each circle represents the number of whelks distinguished by sex.

1979 and 1978 year classes, final biomass represented a more considerable increase, to 13.8 times and 6.2 times the initial biomass, respectively. These whelks also displayed 36.2-fold and 10.8-fold assimilation and 11.2fold and 3.8-fold growth as compared to initial biomass in the respective years, and a low mortality, equivalent to $12.3 \%$ and $10.9 \%$ of assimilation, respectively. Conversely, in the 1976 and $\leqq 1975$ year classes, both assimilation (1.6 times and 0.5 times the initial biomass in the respective years) and growth (34.9\% and $6.4 \%$, respectively) were slight, compared with the 1979 and 1978 year classes, but mortality was 0.6 times and 1.9 times as great as assimilation, respectively. As a result, final biomass of these year classes decreased, respectively, to $60.7 \%$ and $12.6 \%$ of initial biomass. The 1977 year class as well did not show large assimilation, growth, mortality, or final biomass as compared with initial biomass. Its energy budget showed an intermediate pattern between those of the 1979-1978 year classes and the 1976- $\leqq 1975$ year classes.

The turnover ratio in the neptune whelk population during the investigation period was 0.42 , reflecting substantial mortality in the $\leqq 1975$ year class. 


\section{0 year class $(0)$}

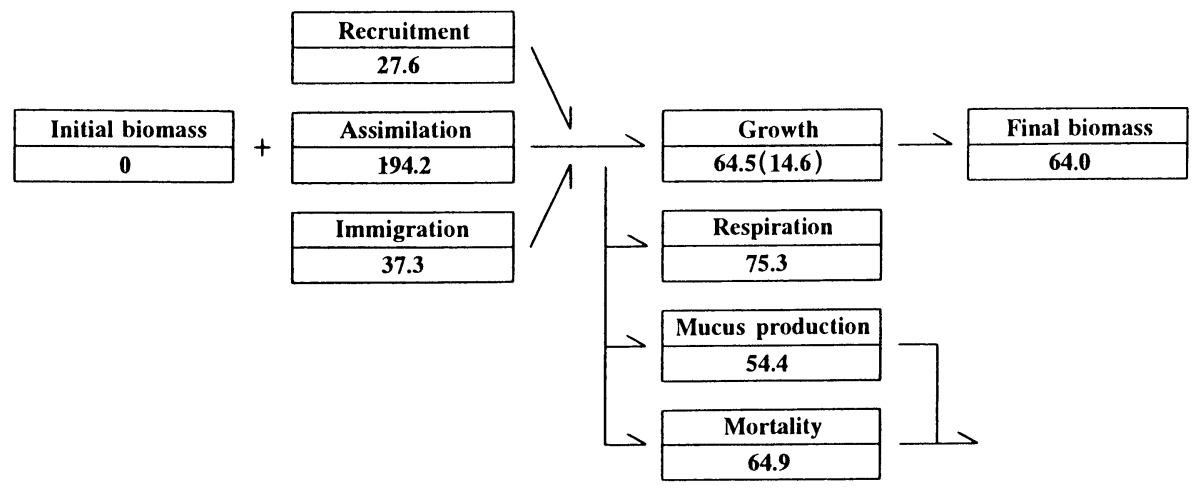

1979 year class $(0-I)$

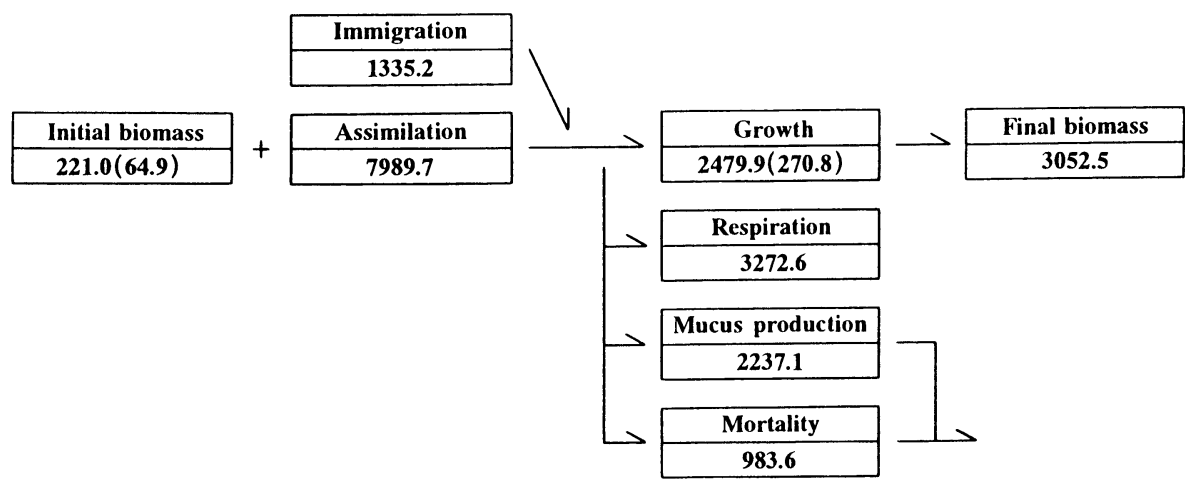

1978 year class $(\mathrm{I}-\mathrm{II})$

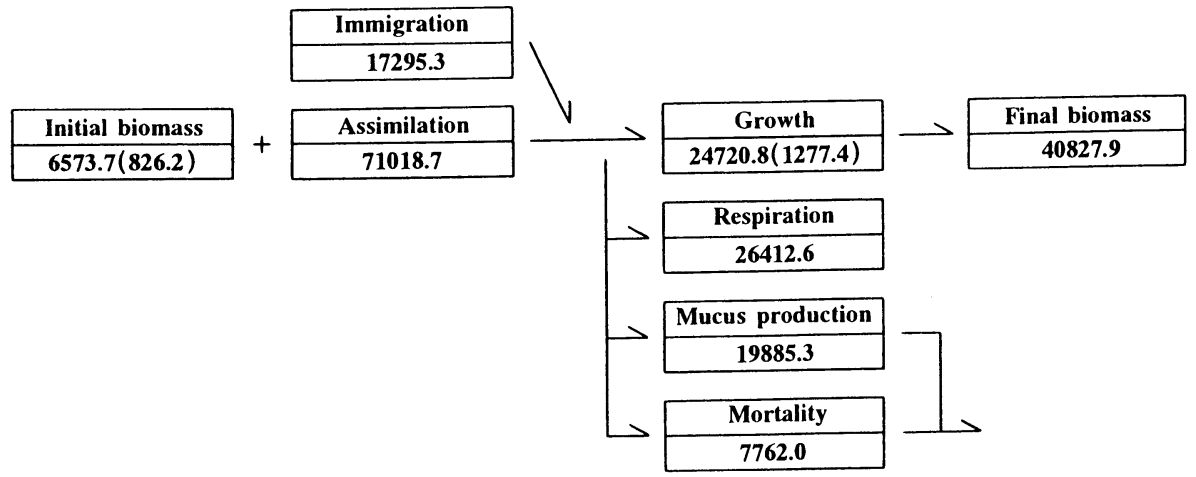

Fig. 3. The annual energy budgets of the 1980, 1979, and 1978 year-classes of Neptunea arthritica in Usu Cove. Except for biomass, the budgets are expressed in $\mathrm{J} \cdot \mathrm{m}^{-2} \cdot$ year $^{-1}$, and biomass in $\mathrm{J} \cdot \mathrm{m}^{-2}$. Roman and Arabic numerals in parentheses indicate ages and energy directed to the shell, respectively. 
1977 year class $(\mathrm{II}-\mathrm{III})$

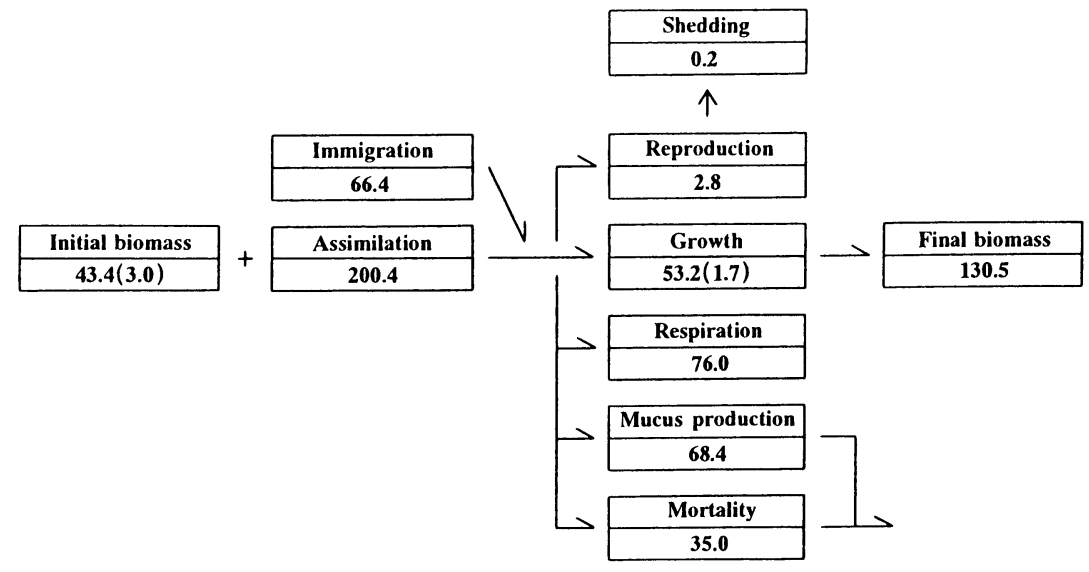

\section{6 year class $(\mathrm{III}-\mathrm{IV})$}

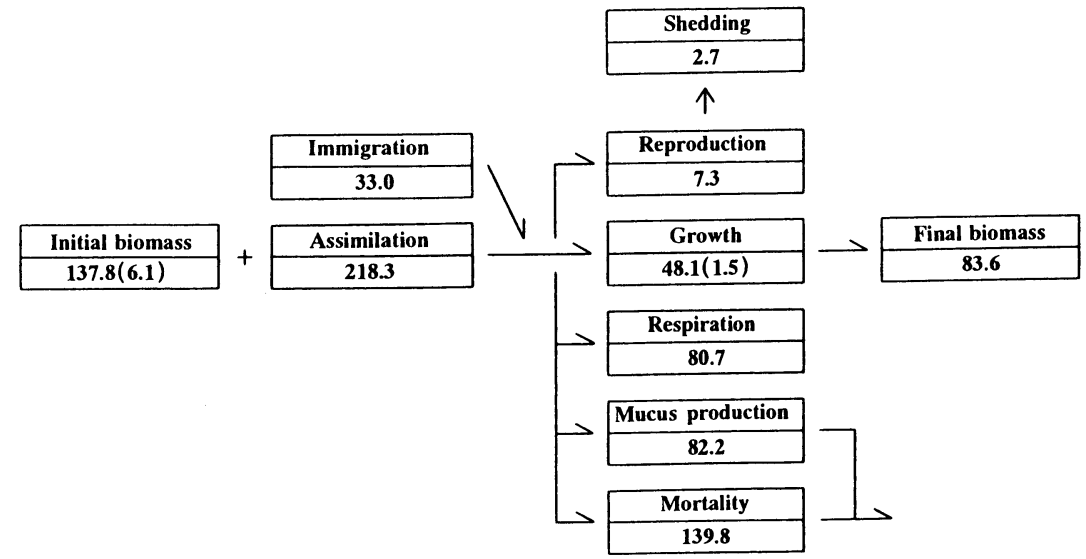

\section{$\leqq 1975$ year class $(\geqq \mathrm{IV}-\geqq \mathrm{V})$}

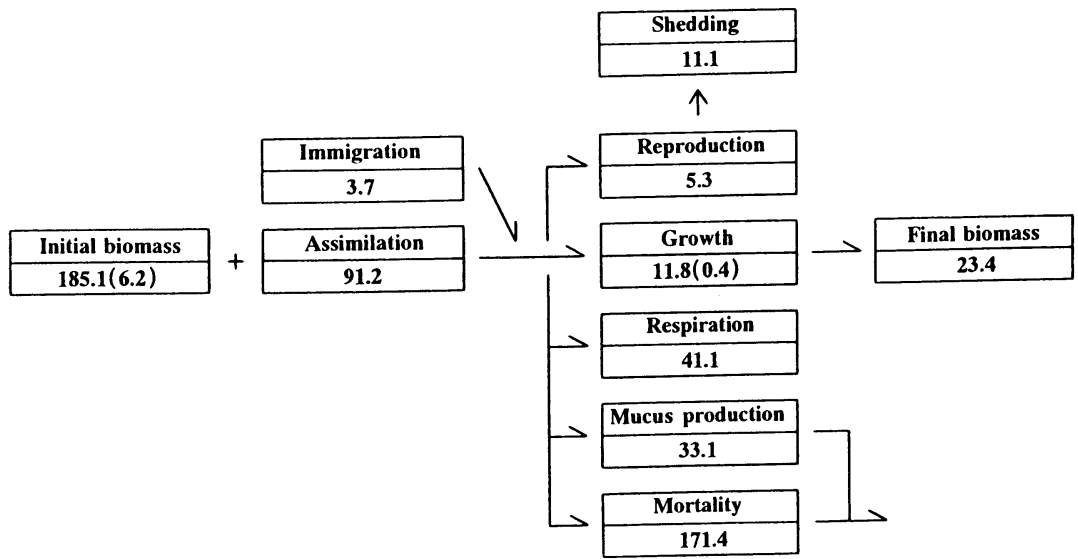

Fig. 4. The annual energy budgets in the 1977, 1976, and $\leqq 1975$ year-classes. Except for biomass, the budgets are expressed in $\mathrm{KJ} \cdot \mathrm{m}^{-2} \cdot \mathrm{year}^{-1}$, and biomass in $\mathrm{KJ} \cdot \mathrm{m}^{-2}$. 


\section{DISCUSSION}

Mucus production has been studied in some species of marine mollusc (see Davies \& Hawkins 1998), including Buccinum undatum (Kideys \& Hartnoll 1991), like $N$. arthritica, a member of the Buccinidae. In the present study, however, the energy budget of the population was not examined in terms of food consumption, but in terms of assimilated energy. The work of Peck et al. (1987) shows how to calculate the proportion of mucus production to assimilated energy and points out a deficiency in our study. It is necessary to estimate a more precise budget by measuring mucus production several times throughout a year, and moreover, by examining the biological production in terms of food consumption rather than in terms of assimilation .

The sex ratio of adult neptune whelks changed with each sample taken. Cole (1942) and MacKenzie (1961) showed that a difference in behavioural pattern between male and female can cause a seasonal change in the sex ratio in Urosalpinx cinerea and Eupleura caudata, respectively. Fujinaga and Nakao (1994) reported that habitats change in relation to reproductive and feeding activities in adult whelks in Usu Cove. Many adults aggregate in egg mass deposition sites with substrata suitable for spawning, such as rocks and boulders, during the spawning period. After spawning, these whelks rapidly migrate to places with abundant food. Migration thus likely plays a role in the seasonal change in the sex ratio of the neptune whelk. However, no pattern in the changes was evident in the present study, and the energy budgets of year classes had to be estimated on the basis of the sex ratio calculated by interpolation (0.95) at the midpoint of the period of population density measurements. In the future, the construction of a more accurate energy budget of the population will require a more detailed investigation of the sex ratio, and further, an examination of the difference in mortality rates between males and females (Moore 1937; Pearce \& Thorson 1967).

The energy budget patterns were different between the 1980 year class, the $1979 \cdot 1978$ year classes, the 1977 year class, and the $1976 \bullet \leqq 1975$ year classes, based on the relations among initial biomass (recruitment), assimilation, growth, mortality, and final biomass. In Usu Cove, neptune whelks older than 3 years old constitute the adult population; females spawn for the first time in May and June at the end of the fourth year (Fujinaga 1985, 1987). This means that the 1977 year class, which passed from the II to III age- group during the investigation period, corresponded to the stage of transition from the immature to the adult population. The energy budgets of the neptune whelk population in Usu Cove may thus be nearly understood in terms of the growth stages of hatchlings (the 1980 year class), immature whelks (the 1979 and 1978 year classes), and adults (the 1976 and $\leqq 1975$ year classes).

Although in hatchlings assimilation was several times as large as recruitment, final biomass did not show a very great increase, because of the rather high mortality. In the immature population, final biomass increased to several times or more the initial biomass, with not less than 10-fold larger assimilation and high growth as compared with the initial biomass, and with mortality equivalent to a little over $10 \%$ of assimilation. On the other hand, in the adult population, final biomass substantially decreased due to assimilation roughly equal to or less than initial biomass and little growth, and mortality roughly equal to or exceeding assimilation.

Fujinaga and Nakao (1998) suggested that, for artificially enhancing the propagation rate of the neptune whelk, it is necessary to enhance hatching rates by setting in place large, hard substrata suitable for egg mass deposition, in addition to the resource management of adults, such as the regulation of catch size and the establishment of a closed season for fishing. The energy budget patterns in the growth stages mentioned above suggest another necessary consideration, namely the guarantee of food organisms to support a substantial increase of biomass in the immature population. The neptune whelk is said to be a scavenger, but the amount of carrion needed to maintain a scavenging snail population is not thought to occur in natural environments (Kent 1983; Himmelman \& Hamel 1993). Also, Fujinaga and Nakao (1999b) reported that the neptune whelk may feed more often as a predator than as a scavenger. Furthermore, immature whelks center their distribution in places with abundant food organisms over the whole year (Fujinaga \& Nakao 1994). These facts suggest that merely enhancing hatching rates will not be effective unless a nursery ground to secure food organisms for the immature population is prepared. In particular, the construction of such a nursery ground may be essential for the recovery of the neptune whelk fishery in embayments subjected to destructive damage by the use of TBT compounds, because these compounds have caused deleterious effects on various marine organisms (Evans et al. 1995; Smith 1996), including the food organisms of the neptune whelk. 
The turnover ratio of the neptune whelk population in the density investigation period was low, 0.42 , because of the substantial mortality in the older adult population. This value means that the population in Usu Cove is far from the stage at which the population can maintain itself, and that means to drastically decrease the mortality, such as a fishing moratorium ranging over several years, may be needed for recovery of the population. The same conclusion was more cautiously hinted at in our earlier paper on population structure and mortality (Fujinaga \& Nakao 1996). In a study on population structure, it is difficult to accurately estimate the degree of recovery in the population that will follow upon a change in mortality rates, because production and change in standing stock (in weight) cannot be assessed. In the future, it will be desirable to present a forecast of the degree of recovery with changing mortality rates, on the basis of the energy budget.

Acknowledgments. We thank Dr. Akira Fuji, Professor Emeritus of Hokkaido University, for his guidance and encouragement, and Dr. Kei Kawai for reading the manuscript. Thanks also go to the late Mr. Masao Ishikawa of the Muroran Branch of the Hokkaido Hakodate Fisheries Experimental Station for his valuable assistance in the field. Mr. Hiroshi Kanbe of the Usu Fisheries Cooperative Association offered us the opportunity to undertake this study, for which we are grateful.

\section{REFERENCES}

Branch, G. M. 1981. The biology of limpets: physical factors, energy flow and ecological interactions. Oceanography and Marine Biology: An Annual Review, 19: 235380 .

Cole, H. A. 1942. The American whelk tingle, Urosalpinx cinerea (Say), on British oyster beds. Journal of the Marine Biological Association of the United Kingdom, 25: 477-508.

Davies, M. S. and S. J. Hawkins 1998. Mucus from marine molluscs. Advances in Marine Biology, 34: 1-71.

Evans, S. M., T. Leksono and P. D. McKinnell 1995. Tributyltin pollution: a diminishing problem following legislation limiting the use of TBT-based anti-fouling paints. Marine Pollution Bulletin, 30: 14-21.

Fujinaga, K. 1985. The reproductive ecology of the neptune whelk (Neptunea arthritica Bernardi) population, with special reference to the reproductive cycles, depositions of egg masses and hatchings of juveniles. Bulletin of the Faculty of Fisheries, Hokkaido University, 36: 87-98 (in Japanese with English abstract).

Fujinaga, K. 1987. On the growth pattern of the neptune whelk, Neptunea arthritica Bernardi. Bulletin of the Faculty of Fisheries, Hokkaido University, 38: 191-202.

Fujinaga, K. and S. Nakao 1994. Migration pattern of Neptunea arthritica Bernardi, with special reference to relations with reproductive and feeding activities. Japanese Journal of Ecology, 44: 331-338 (in Japanese with English abstract).

Fujinaga, K. and S. Nakao 1996. Population structure and mortality of the neptune whelk Neptunea arthritica in Usu Bay, southern Hokkaido. Nippon Suisan Gakkaishi, 62: 184-188.

Fujinaga, K. and S. Nakao 1997. Seasonal change in assimilation energy of Neptunea arthritica. Nippon Suisan Gakkaishi, 63: 10-16 (in Japanese with English abstract).

Fujinaga, K. and S. Nakao 1998. Substratum preference and predation rates on embryos at spawning sites in Neptunea arthritica. Suisanzoshoku, 46: 19-24.

Fujinaga, K. and S. Nakao 1999a. A decline in RPS index of Neptunea arthritica in Usu Cove. Suisanzoshoku, 47: 457-458.

Fujinaga, K. and S. Nakao 1999b. Food organisms and food consumption rates in Neptunea arthritica. Suisanzoshoku, 47: 15-20.

Himmelman, J. H. and J.-R. Hamel 1993. Diet, behaviour and reproduction of the whelk Buccinum undatum in the northern Gulf of St. Lawrence, eastern Canada. Marine Biology, 116: 423-430.

Itoh, H. and S. Tachizawa 1981. An estimation of the density of the available stock of a sea snail, Neptunea arthritica, by trap fishing. Bulletin of the Hokkaido Regional Fisheries Research Laboratory, 46: 113-119.

Kawanabe, H. 1969. Terms and symbols on the biological production. In, Methods for Assessment of the Biological Production in Fresh Waters, Mori, S. (ed.), Kodansha, Tokyo, pp. 1-7.

Kent, B. W. 1983. Patterns of coexistence in busyconine whelks. Journal of Experimental Marine Biology and Ecology, 66: 257-283.

Kideys, A. E. and R. G. Hartnoll 1991. Energetics of mucus production in the common whelk Buccinum undatum L. Journal of Experimental Marine Biology and Ecology, 150: 91-105.

MacKenzie, C. L. 1961. Growth and reproduction of the oyster drill Eupleura caudata in the York River, Virginia. Ecology, 42: 317-338.

Moore, H. B. 1937. The biology of Littorina littorea. Part 
I . Growth of the shell and tissues, spawning, length of life and mortality. Journal of the Marine Biological Association of the United Kingdom, 21: 721-742.

Pearce, J. B. and G. Thorson 1967. The feeding and reproductive biology of the red whelk, Neptunea antiqua (L.) (Gastropoda, Prosobranchia). Ophelia, 4: 277-314.

Peck, L. S., M. B. Culley and M. M. Helm 1987. A laboratory energy budget for the ormer Haliotis tuberculata L. Journal of Experimental Marine Biology and Ecology, 106: 103-123.
Smith, P. J. 1996. Selective decline in imposex levels in the dogwhelk Lepsiella scobina following a ban on the use of TBT antifoulants in New Zealand. Marine Pollution Bulletin, 32: 362-365.

Wright, J. R. and R. G. Hartnoll 1981. An energy budget for a population of the limpet Patella vulgata. Journal of the Marine Biological Association of the United Kingdom, 61: 627-646. 